\title{
"Ter câncer mudou minha vida": cartografia de Luiza na micropolítica das redes de cuidado oncológico
}

\author{
I 1 Mariana Pompílio Gomes Cabral, ${ }^{2}$ Maria Salete Bessa Jorge, \\ ${ }^{3}$ Túlio Batista Franco, ${ }^{4}$ Evelyne Viana de Franca I
}

Resumo: Garantir cuidado integral à saúde de mulheres com câncer cérvico-uterino ainda é um desafio para a Saúde Coletiva, embora se evidencie o enraizamento de políticas, práticas e saberes na conformação de redes oncológicas de cuidado. Este estudo apostou na necessidade de mergulhar nas experimentaçóes da micropolítica do cuidado para conhecer as nuances do fenômeno investigado. Ao fundamentar-se no aporte teórico-metodológico de Deleuze e Guattari, objetivou-se cartografar linhas de composição da produção de cuidado oncológico, na cidade de São Luís-MA, tendo como dispositivo a rede da usuária-guia Luiza. Investigaram-se 28 participantes através de entrevistas em profundidade e rodas de conversas. Como resultado, desenhou-se uma rede vulnerável, fragmentada e centralizada no cuidado biomédico, tendo um hospital que acolhe demandas da doença e uma atenção primária que abandona prevenção e promoção de saúde. Destaca-se a importância de conhecer a mulher com câncer atrelada à comunidade, à religiosidade e aos vínculos familiares. Ter câncer mudou a vida de Luiza e demandou conexôes para além do biomédico. Essa cartografia convoca à percepção dos gargalos existentes na produção de redes oncológicas, convidando a quebrar muros tecnoassistenciais e criar enfrentamentos centrados na promoção de saúde e qualidade de vida.

> Palavras-chave: câncer de colo uterino; cuidado; micropolítica; cartografia; redes de atenção à saúde.

Recebido em: 21/01/2019 Revisado em: 06/05/2019 Aprovado em: 25/05/2019 


\section{Introdução}

$\mathrm{O}$ argumento basilar deste estudo está na perspectiva de que não há como negar o afetamento do câncer cérvico-uterino em mulheres, considerado um grave problema e um desafio no contexto da saúde coletiva. Embora seja uma das neoplasias com maior potencial de cura, se diagnosticado e tratado precocemente, a estimativa para o Brasil assemelha-se ao perfil epidemiológico da América Latina, onde o câncer de colo do útero (CCU) figura entre os principais acometimentos de câncer feminino, tendo por expectativa para o biênio 2018-2019, a ocorrência de 600 mil casos novos (INCA, 2017).

Diante desse agravamento, estudos apontam que o cuidado oncológico exige uma complexidade para além de uma atenção pontual, médica e hospitalar. Para tanto, foi preciso fomentar uma assistência intersetorial, articulada e territorializada, em que surgem a Política Nacional de Atenção Oncológica (BRASIL, 2005) e a implantação das Redes de Atenção à Saúde, tendo como proposta uma nova organização da assistência, além de instituir quatro redes temáticas prioritárias (BRASIL, 2011), dentre elas, a Rede de Prevenção e Qualificação do Diagnóstico e do Tratamento do CCU e de Mama (SOARES et al., 2011).

A nova conjuntura de políticas públicas para o enfrentamento dessa neoplasia preconiza produzir cuidado em rede, construindo conectividade entre açôes, serviços e estratégias de prevenção, promoção de saúde, tratamento, reabilitação e cuidados paliativos, com o objetivo de expandir e articular o cuidado entre as diversas áreas componentes do processo oncológico (BRASIL, 2011). No limite, é uma proposta de transformação da clínica tradicional, em que a assistência a pessoas com câncer se torna universal e integral. Há de se convir que é um grande avanço o fomento à organização de uma rede oncológica, a considerar que nem sempre o câncer foi tratado como um problema de saúde pública, carregando hegemonicamente o legado de ser um campo biomédico e hospitalocêntrico, centralizado na doença, no diagnóstico, nos procedimentos e tecnologias de alto custo para uma terapêutica resolutiva (TEIXEIRA; PORTO; HABIB, 2012).

A produção do cuidado em rede no enfrentamento às doenças crônicas não transmissíveis é uma perspectiva desafiadora (RAUPP et al., 2015), pois embora existam preconizaçóes ratificadas em lei, este estudo parte da perspectiva de que toda rede de cuidado é produzida em seu território micropolítico (FRANCO; MERHY, 
2012), com contornos e multiplicidades que surgem no cotidiano singular dos serviços de saúde e na relação entre gestores, profissionais, usuários e familiares. Sendo assim, mesmo havendo uma rede desenhada através das conformações políticas, o caminho percorrido para produzir cuidado não é único. Pelo contrário, a produção de redes envolve processos múltiplos de subjetivaçôes, movimento, autonomia e singularização, além de envolver uma estrutura histórico-social, cultural e enconômica que se determina em cada território (AMARAL; BOSI, 2017; MERHY et al., 2014).

À vista disso, a concepçáo de rede neste estudo emerge da compreensão de um desenho rizomático do modo de produção do cuidado. Para Deleuze e Guattari (1995), o rizoma, conceito vindo da botânica, rompe com a representação de rede normatizada, serializada, pontual, causal e linear. Nele, nenhum modelo estruturado justifica ou gera, por si só, sua produção. Cada rizoma é único e de caráter heterogêneo, com intercessóes e fluxos, construindo conexôes de acordo com as necessidades e possibilidades existentes.

$\mathrm{Na}$ macropolítica da seara oncológica, os desafios para atingir a integralidade se constituem desde a gestão em saúde, que escolhe e organiza os desenhos de fluxos e caminhos para a conformação de uma rede de cuidado, a determinantes não exclusivos do âmbito da saúde, considerando que a conjuntura sócio-política também produz impactos nos processos saúde-doença da população (BRITO-SILVA et al., 2014). Já na micropolítica, concomitante às barreiras sociais e de gestão em saúde, as pesquisas refletem que as subjetivaçôes na atenção às mulheres com câncer tornam o cuidado mais complexo e delicado à medida que surgem elementos que precisam de intervençôes interdisciplinares, envolvendo questôes de gênero, corpo e sexualidade, além de demandas psicológicas interligadas ao imaginário da dor, sofrimento e morte (RICO; IRIART, 2013).

Ou seja, nesse emaranhado de determinantes, defende-se neste escrito que a produção de redes de cuidado oncológico é um processo com múltiplos desdobramentos, com potencialidades e desafios que emergem tanto no cotidiano dos serviços de saúde, seja na atenção primária ou especializada - com gestores, trabalhadores, profissionais de saúde e usuários -, como em nível cultural, social e subjetivo, envolvendo as especificidades e singularidades da relação entre os sujeitos, a sociedade, o cuidado, a vida e o adoecimento oncológico.

Portanto, foi com o olhar pluralizado e complexificado que foram elencadas algumas questôes norteadoras desta pesquisa: quem são essas mulheres que 
experienciam o adoecer oncológico? Quais os caminhos possíveis, escolhidos e percorridos na produçáo do cuidado? Como se desenham suas redes de cuidados? Quem produz cuidado? Que modelo de produção de cuidado se estabelece?

Reconhecendo a relevância da temática, este estudo teve como objetivo geral cartografar as redes de cuidados de Luiza, uma mulher que há cinco anos percorre e produz caminhos do cuidado no enfrentamento a um CCU. De modo específico, a proposta foi conhecer os personagens, as experiências e os serviços envolvidos na produção do cuidado, mapeando as linhas de composição das redes no território micropolítico e problematizando tais conexôes com as possibilidades de produção de vida e de saúde de mulheres com câncer.

\section{Metodologia}

Com a intençáo de mapear a micropolítica das redes de cuidado de mulheres com câncer, esta pesquisa enveredou pela abordagem qualitativa, centrada na investigação cartográfica, sendo esta a processualidade teórico-metodológica que norteou os caminhos deste estudo.

Mas, afinal, o que é uma cartografia? Gilles Deleuze e Félix Guattari, teóricos da filosofia pós-estruturalista, se apropriam do termo cartografia - que tem origem na geografia - utilizando-o como ferramenta para a construção do desenho de paisagens sociais (ROLNIK, 2007). A cartografia desenha as linhas intercessoras da vida, e dessa forma, os mapas cartográficos estão para além de aspectos físicos e geográficos, são mapas existenciais (GUATTARI; ROLNIK, 1986).

A cartografia, enquanto método de investigação na pesquisa qualitativa, rompe com concepções essencialistas e absolutistas, que se concentram na produçấo de conhecimento através da relação direta entre um sujeito identitário e um objeto a ser analisado. Pelo contrário, esse método é por excelência um modo de acompanhar processos (PASSOS; KASTRUP; ESCÓSSIA, 2010), o que significa que as estratégias metodológicas em uma pesquisa cartográfica vão se construindo na relação com o próprio campo, de forma processual, sendo também dispositivo a disparar conexôes em singularidade e multiplicidade (SCHÖPKE, 2012), convidando a produzir o elo entre pesquisa e vida, através da produção de conhecimento e do encontro entre o cartógrafo e o rizoma pesquisado.

Cartografar é partir da perspectiva de que é impossível conhecer a totalidade do investigado, visto que o fenômeno é inacabado e inesgotável. Por isso, o alcance em 
análise não se absolutiza, referindo-se, desse modo, ao desenho de pistas cartográficas, que se mantiveram lado a lado, sem hierarquia, operando não por unificaçáo ou totalização, mas no plano comum de imanência das diferenças (PASSOS; KASTRUP; ESCÓSSIA, 2010). O cartógrafo-pesquisador assume um compromisso com a experimentação do campo, ao acompanhar os movimentos nos diversos territórios.

Nesta pesquisa, o rizoma pertence à vida de mulheres com câncer e às linhas de composição de redes de cuidado. A imersão em campo privilegiou o trabalho com o coletivo em horizontalidade, percebendo as conexóes e os pontos intercessores que favorecem a coexistência e/ou a exclusão dos diversos elementos da produção do cuidado em rede. Tendo como campo o território de São Luís-MA, iniciou-se a busca de mulheres com câncer que pudessem se tornar usuárias-guia da pesquisa. O conceito de usuário-guia (GOMES; MERHY, 2014) é o dispositivo central e disparador desta pesquisa, pois considera o usuário o protagonista primordial na tessitura de redes de cuidado.

Sistematizando, esta cartografia contou com 28 participantes, que contemplaram o desdobramento das três etapas da pesquisa. A primeira foi primordial para conhecer a gestáo do cuidado dos principais componentes da rede, dentre eles, os serviços de alta e média complexidade, além da atenção primária. A investigação aconteceu através de quatro entrevistas em profundidade com dois articuladores da rede oncológica, um da Secretaria Estadual de Saúde e um da Secretaria Municipal de Saúde.

De posse desses conhecimentos, na segunda etapa, realizou-se uma roda de conversa com coordenadores do hospital municipal (1), hospital estadual (1) e unidades básicas de saúde (3); e 15 profissionais da saúde, dentre eles, sete pertencentes à Atenção Primária (1 médico, 3 enfermeiros e 3 agentes comunitários de saúde); quatro do Hospital Municipal (3 enfermeiras e 1 Psicóloga); e quatro do Hospital Estadual (1 médica, 1 enfermeira e 2 fisioterapeutas), com o intuito de apresentar a proposta metodológica e convidá-los a discutir casos oncológicos complexos que tensionassem a rede na qual eles operavam.

Dessa roda de conversa, foram escolhidos alguns casos e a partir destes, desenhouse a terceira etapa. Buscando compreender trajetórias de cuidado, apresenta-se a rede da usuária-guia Luiza, composta por seis personagens envolvidos na micropolítica do cuidado: Maria (companheira) e Liliane (filha); uma agente comunitária de saúde 
(ACS); uma coordenadora da Estratégia Saúde da Família (CESF); 1 enfermeira (ENF); um coordenador do hospital oncológico (CH). Na terceira etapa, foram utilizadas algumas ferramentas para a produção de encontros, tais como a realização de rodas de conversa, entrevistas, observação e diário de campo. A pesquisa se desenvolveu de janeiro de 2015 a dezembro de 2016.

Essas três etapas foram fundamentais para a compreensão da rede oncológica maranhense e subsidiaram a análise dos dados, realizada a partir da confecção de mapas existenciais que capturaram as linhas de composição da cartografia de Luiza. $\mathrm{Na}$ análise, foram estabelecidas interfaces da produção dos dados em campo com os conceitos teóricos que embasam a metodologia abordada e os achados científicos sobre determinadas temáticas.

O artigo em questão é fruto de uma dissertação de mestrado e trata do recorte de uma pesquisa nacional chamada "Observatório nacional da produçáo de cuidado em diferentes modalidades à luz do processo de implantação das Redes Temáticas de Atenção à Saúde no Sistema Único de Saúde (SUS): avalia quem pede, quem faz e quem usa", e atende ao disposto na Resolução CNS no 466/2012 sobre pesquisa envolvendo seres humanos, com parecer no 560.597, de 23 de março de 2014.

\section{Resultados e Discussão}

Essa cartografia se apresenta como ferramenta teórico-metodológica e de prática social que investigou o alinhamento de estruturas no nível macropolítico e explorou o potencial performativo complexo e contingente dos protagonistas na micropolítica do cuidado. Discute-se, portanto, a complementaridade dos dados produzidos em campo a partir da abertura à experimentação, a fim de problematizar a redes temáticas em saúde e a rede oncológica partir de suas múltiplas formas do cuidar.

A cartografia de Luiza seráaqui apresentada com as seguintes linhas intercessoras: (1) A trama das redes de cuidado oncológico e a cartografia: quem é Luiza? Por que Luiza?; (2) A formação do corpo-vida com câncer e seus desdobramentos; (3) O hospital que acolhe a doença: o campo oncológico tensionado pela dimensão biomédica; (4) A atenção primária que abandona da prevenção à reabilitação; (5) A potência do território comunitário: redes que tecem vínculos e produemz vida; (6) O que aprendemos com a cartografia de Luiza? Desafios da produção do cuidado oncológico. 


\section{A trama das redes de cuidado oncológico e a cartografia: quem é Luiza? Por que Luiza?}

O método cartográfico exige uma mudança das práticas de narrar (PASSOS; BARROS, 2009) e, por isso, é preciso, a priori, desenhar Luiza para que o leitor se aproxime de forma sensitiva aos encontros desta cartografia. A usuária-guia, doravante denominada Luiza, é uma mulher de 58 anos, negra, de baixa estatura, cabelos castanhos, sempre presos. Destaca-se sua magreza, que aparentava fraqueza. Tímida, com baixo tom de voz e narrativas que, por vezes, revelavam uma mulher sutil, que travava uma conversa pausada, com poucas palavras. Luiza contou sua história de vida entrelaçada à descoberta do CCU e ao tratamento oncológico, entre sorrisos e lágrimas.

Por que Luiza? As narrativas sobre a vida dessa usuária chamaram atenção, pois chegaram às escondidas. De modo particularizado, a agente comunitária de saúde (ACS) Fernanda relatou o caso de Luiza somente após o término da roda de conversa realizada entre profissionais da atenção primária e terciária de saúde:

Não falei na roda de conversa por que esse caso é delicado. Luiza é minha vizinha, mas não pertence à área que eu acompanho; e onde eu moro é uma área descoberta (sussurrando). Luiza tem câncer de colo uterino e faz tratamento só no hospital, ela nunca foi acompanhada pelo posto (ACS).

O relato velado da ACS já produz uma abertura à cartografia de Luiza: que especificidades envolvem as redes de cuidado de uma usuária reconhecida por uma trabalhadora da saúde que a acompanhava apenas nos seus entornos comunitários, mas que por sua vez, era uma área descoberta pela atenção primária? Diante desse cenário, a ACS narra o caso também como um pedido de ajuda, percebendo a pesquisa como ferramenta de intervenção e visibilidade às redes de cuidado de Luiza e seus atravessamentos.

Outra abertura a se destacar foi identificada mediante o fato de Luiza não ser acompanhada pela atenção primária e, por isso, o ponto de partida para estabelecer os encontros cartográficos seriam na casa da usuária. Ora, desdobrar as nuances da vida de uma mulher que experienciou a formação de seu corpo com câncer em seu próprio território tornou-se mais uma linha interessante a se desdobrar, pois, frequentemente, só era possível encontrar as usuárias nos hospitais ou nas unidades básicas de saúde, deslocadas dos seus espaços comunitários e existenciais. 
A cartografia de Luiza se expressou como um caso que tangenciava e tensionava as formalidades da rede de assistência oncológica, produzindo, mediante o rigor da investigação cartográfica, uma multiplicidade de linhas de fuga, de escape e de vida em relação à estratificação estrutural. Isto posto, desejando a experimentação irredutível aos movimentos da subjetividade e da paisagem existencial, aceitou-se o desafio e seguiu-se adiante em busca da usuária-guia.

\section{A formação do corpo com câncer e seus desdobramentos}

A formação de Luiza e seu corpo com câncer teve início há cinco anos. Após diagnóstico, fez tratamento cérvico-uterino com quimioterapia e radioterapia, sem indicação de realização de cirurgia. $\mathrm{O}$ primeiro momento junto à usuáriaguia foi de captura das narrativas de descoberta do câncer e dos processos de subjetivaçôes emergentes:

Foi de repente. Eu estava fazendo uns trabalhos pesados no quintal, quando comecei a sentir uma dor forte nas costas, que foi acochando, até ficar insuportável. Mas rapidinho uma prima de Maria, que trabalhava na saúde, conseguiu marcar uma consulta no hospital oncológico (LUIZA).

Esse discurso já evidencia, minimamente, duas linhas de composição da descoberta do corpo com câncer. O primeiro concentra-se no modo singular de perceber os sintomas oncológicos. Luiza afirma que antes desse episódio não sentia dores "tão fortes a ponto de incomodar, eram aquelas dores da vida mesmo, sabe? Dor nas costas, nas pernas, mas que pareciam normais" (Luiza). Ou seja, narra a dificuldade em descobrir a doença apenas pelos sinais do corpo, já que havia uma rotina de dores habituais, principalmente após realizar atividades domésticas. Diante disso, a educação em saúde tem repercutido na adesão à realização periódica do exame citopatológico, que permanece sendo o critério mais adotado para o rastreamento e que, comprovadamente, impacta desde o diagnóstico precoce à escolha do plano terapêutico (ALVES; ALVES; ASSIS, 2016). Embora a cobertura e adesão ao exame preventivo do CCU tenha se tornado crescente na atenção primária (INCA, 2016), ainda há casos como o da usuária-guia, que refletem as fragilidades nesses fatores.

Luiza discute também uma realidade da saúde pública, afirmando que para investigar o adoecimento, entrou na rede oncológica através de um vínculo informal de sua rede de relaçóes e não necessariamente o fluxo preconizado da rede oncológica formal. Comenta que "[...] se não fosse essa pessoa, eu nem sabia como conseguir 
uma consulta, tem toda uma burocracia, né? Mas da forma que eu tava, se eu ainda fosse esperar, eu acho que tinha morrido [...]”. Luiza aponta seu desconhecimento, incialmente, sobre os sinais e sintomas da doença, e posteriormente, sobre a rede de saúde. A mesma também faz uma crítica às dificuldades de acesso ao campo oncológico, procurando uma pessoa de sua rede social de apoio que a guiasse.

Essas questôes são amplamente discutidas nas produçôes científicas acerca da integralidade do cuidado a mulheres com câncer (BRITO-SILVA et al., 2014; RAUP et al., 2015), que investigam como as diversas barreiras de acesso coadunam com o maior índice de morbimortalidade. Isso vai de encontro às recomendaçóes da Política Nacional de Atenção Oncológica (BRASIL, 2005), que preconiza a implementação de linhas de cuidado para a consolidação da rede, com pactuação dos fluxos entre os serviços para facilitar o acesso à assistência integral às mulheres, desde a prevenção ao diagnóstico, tratamento e reabilitação.

Para Luiza, a possibilidade de acesso aconteceu a partir de um vínculo informal na saúde, que faz um furo no protocolo e na burocracia, em nome da responsabilidade afetiva de cuidado com o outro, o que simbolicamente representa a cultura do "jeitinho brasileiro". Segundo Pinto e Najar (2011), o "jeitinho" consiste em elemento central no processo de constituição da identidade brasileira, que se define enquanto uma estratégia de ação social conectada com a empatia e o autogoverno do profissional, que se tornam sujeitos desviantes dos protocolos para atender às necessidades de seus próximos com maior celeridade.

Nesse contexto, é possível refletir sobre os traços culturais da sociedade brasileira no trabalho em saúde, além da fragilidade do acesso aos serviços. A questão não trata somente de uma conduta ética. Discute-se, portanto, umas das raízes dessa problemática: se saúde é um direito de todos e dever do Estado, por que, em alguns casos, é preciso furar a fila para conseguir acompanhamento efetivo para os problemas de saúde, caso contrário, pode morrer esperando? À vista disso, a articuladora da rede oncológica faz uma alerta de que "[m]uito mais do que qualquer outra doença crônica, câncer e tempo andam lado a lado, quanto maior a espera, menor a chance de um bom prognóstico".

Outra conexão rizomática foi a narrativa de Luiza sobre suas travessias para a descoberta do diagnóstico. Segundo ela: "[n]aquele dia, eu soube que estava com câncer e chorei muito. Eu pensei que ia morrer. Eu só pensava onde eu tinha errado. 
E eu só chorava”. A usuária-guia narra como o campo saúde-doença também se produz como processo de subjetivação (FRANCO; MERHY, 2012), ao receber o diagnóstico aliado ao sentimento de tristeza, culpa e arrependimento. Nessa seara, destacam-se os estudos de Sontag (2007), reconhecendo que historicamente o câncer foi visto desde tumor maligno e incurável à tragédia individual, destacando a representação social e simbólica sobre o câncer, que interliga culturalmente o sentimento de culpabilização com a produção do fenômeno. Luiza se emociona ao contar a formação do tratamento oncológico, enfatizando as experiências na quimioterapia e radioterapia:

As duas são horríveis, mas a quimio é pior, porque você vai se desfigurando, emagreci muito, perdi o cabelo, fiquei com a pele feia. E fiquei muito fraca, em todos os sentidos. Porque a dor que a gente sente é toda misturada. É uma dor física, é uma dor na alma. É uma tristeza profunda. Eu só pensava que ia morrer (Luiza).

Faz-se necessário colocar em discussão a multiplicidade de subjetivações que são disparadas quando o processo oncológico se inscreve no corpo humano. Luiza registra como seu corpo, de forma única, sente o acontecimento oncológico - desde a imagem corporal à produção de sofrimento físico e psicológico. A usuária faz menção a um debate importante na Saúde Coletiva e, principalmente, na oncologia: a não-dicotomia entre corpo e mente, físico e emocional. Remete-se à concepção de corpo sem órgãos, de Deleuze e Guattari (2008), que se designa como um reconhecimento prático de um corpo complexo e dinâmico, constituído por uma multiplicidade de outros corpos, mas que também é condição de si próprio. Um corpo desejante, que está para além de uma máquina com órgãos físicos limitados aos seus funcionamentos enquanto corpo orgânico.

Portanto, esta cartografia reflete, enquanto linha de composição rizomática, que a formação do corpo com câncer não é apenas de ordenaçôes físicas e biológicas, pois atravessa diversas esferas do corpo-vida, de modo holístico. Atrelada às condiçóes patológicas, há a experiência do sujeito em proximidade com a finitude humana, além das condiçóes e representaçóes sociais em torno da doença e do doente.

É preciso ratificar essa mestiçagem no ordenamento do rizoma. Quando Luiza declara que seu corpo sente o adoecimento, ela remete à essência da integralidade do cuidado, pois sua experiência se desenha tanto no campo mais específico da saúde, como no encontro com o social, o coletivo e, ao mesmo tempo, na perspectiva singular da vivência oncológica. 


\section{O hospital que acolhe: campo de cuidado oncológico tensionado pela dimensão biomédica}

Na rede oncológica de Luiza, urge a problematização acerca do campo hospitalar, desenhando formas de cuidado ainda na dimensão biomédica. A primeira linha de composição detalha quem são os cuidadores:

O oncologista disse que qualquer problema de saúde eu iria ser atendida lá por eles, fosse uma gripe, ou uma gastrite. Aí durante o tratamento eu só conheci médicos: oncologistas, ginecologistas, até dermatologista. Sou quase doutora também [risos]. Tinham enfermeiros também, mas nunca se identificavam [...].

O panorama que Luiza apresenta é a centralidade do cuidado no hospital oncológico, desde o diagnóstico à reabilitação, além da restrição à equipe médica, não havendo uma rede interdisciplinar, com psicólogo, assistente social e/ou terapeuta ocupacional, dentre outros profissionais, o que fere a proposta da rede oncológica (BRASIL, 2005), que privilegia como princípio norteador o trabalho multiprofissional e em horizontalidade, que permite a conexão heterogênea de políticas, práticas e saberes sob a égide da integralidade do cuidado. Todavia, mais do que acionar dispositivos avaliativos e comparativos entre políticas e práticas, acredita-se que não é possível fazer tal análise sem lembrar-se do panorama histórico da oncologia, que reflete a hegemonia do cuidado na mira da medicina e da alta complexidade. Desse modo, afirmar que câncer não é somente um problema médico e construir redes intersetoriais e de saúde na oncologia ainda é uma luta recente e que caminha na contramão do sistema (TEIXEIRA; PORTO; HABIB, 2012).

Outra composição desse campo se refere ao desconhecimento da usuária sobre algumas etapas de seu tratamento. $\mathrm{O}$ não-saber foi gerador de mais sofrimento. Luiza narra suas impressóes de algumas etapas do tratamento:

Sobre o diagnóstico:

O médico falou primeiro para Maria, mas ela não sabia como me dizer. Só depois que ele veio me dizer o diagnóstico (Luiza).

Sobre não fazer cirurgia:

Eu não fiz cirurgia, mas não sei o porquê. Disseram que no meu caso, não precisaria. Aí não sei se isso é bom ou ruim. Por que muita gente que eu conheço operou (Luiza).

Sobre a realização de exames:

Sempre que eles me passam esse exame é por que eles acham que tem alguma coisa errada. Mas não me disseram para que eu estou fazendo exame. Eu fico noites sem dormir pensando no resultado (Luiza). 
Em tempos de modernização tecnológica, as relaçôes dialógicas estão sendo cada vez mais escassas. Oliveira e Guimarães (2015) despertam para o problema acerca da atuação médica focada na contemplação de todos os aspectos clínicos da neoplasia, preocupando-se exclusivamente com o protocolo clínico, as terapêuticas e os procedimentos. Ou seja, a produção do cuidado é guiada pelo conhecimento restrito à patologia em detrimento da conexão com a pessoa que experiencia essa doença.

Nessa composição, surgem elementos disparadores de análise. Sobre o cuidado em saúde, a rede de Luiza aponta características do que Merhy (2014) caracteriza como trabalho morto, com predominância de uma base material já determinada, realizado de forma automática, apenas incorporando sua prática ao protocolo clínico. A predominância desse modelo, centrado na prescrição protocolar, neste caso faz com que a usuária vivencie um processo de adoecimento sem se apropriar do que está ocorrendo e sem se empoderar. Em contraposição, o trabalho vivo se utiliza de uma gama de ferramentas tecnológicas, conectando o conhecimento médico ao diálogo, escuta, acolhimento. Em suma, a cartografia de Luiza denuncia que o cuidado também pode gerar adoecimento, e convida à reflexão sobre a possibilidade de um cuidado cuidador.

Os médicos cuidadores de Luiza não participaram da pesquisa. A ginecologista alegou seus horários corridos, troca de plantâo e grande demanda para atendimento. Já o oncologista, em nenhuma tentativa de encontro se dispôs a receber os pesquisadores, sem nenhuma justificativa. $\mathrm{O}$ médico-diretor do hospital lamentou a dificuldade de reunir os profissionais para participarem da pesquisa: "Infelizmente nem eu consigo marcar uma reuniáo com toda a minha equipe médica. $O$ hospital náo pode parar. É sempre um corre-corre".

A ausência do corpo médico na pesquisa, em conexáo com os olhares dos pesquisadores em campo, permite fazer um paralelo sobre a forma de captura do trabalho pela lógica capitalística de produção (FRANCO, 2015), muito vista na área da saúde. A preocupação é com o cuidado produzido em série, de forma isolada, o que diverge da proposta do SUS, do campo da Saúde Coletiva, e mais especificamente, da Política Nacional de Atenção Oncológica, que afirma a centralidade nas necessidades do usuário e na articulação de redes de serviços, sob a égide da integralidade do cuidado. 


\section{A atenção primária que abandona da prevenção à reabilitação}

O rizoma de Luiza encontra um nó na conexão entre atenção primária e prevenção oncológica. Quando indagada, responde: "Como assim, prevenção no posto? Só fui ao posto para extrair dente”. Esse estranhamento acerca de procedimentos preventivos e sua relação com a unidade básica de saúde sinaliza a lacuna da atenção básica enquanto espaço de promoção da saúde, acompanhamento de doenças crônicas e detecção precoce do câncer cérvico-uterino.

No nível da gestão, as percepçôes complementam essa problemática:

A atenção primária é para ser porta de entrada, né, não somente oncologia. Mas o que temos é uma atenção básica fragilizada. Se você for ver, as mulheres com câncer que estão morrendo, dificilmente tiveram diagnóstico precoce na atenção primária. Mas aí porque não estão, é um problema bem maior, estrutural, de capacidade territorial, capacitação técnica, investimento de recursos, tudo isso (GT1).

Sabe-se que o campo da prevenção é fundamental no que concerne ao CCU, pois há probabilidade de um bom prognóstico se diagnosticado precocemente (INCA, 2018). A Política Nacional de Atenção Oncológica, juntamente com a organização das redes temáticas em saúde, prioriza uma rede específica de câncer de mama e colo uterino. Destacam-se, dentre seus componentes fundamentais, a atenção básica e as equipes da Estratégia Saúde da Família, que têm por diretrizes operacionalizar a previsão de ações voltadas para a promoção da saúde, a prevenção do câncer, o diagnóstico precoce, o apoio à terapêutica, aos cuidados paliativos e ao seguimento dos doentes (BRASIL, 2011). Reforça-se, portanto, a atenção primária como a principal porta de entrada das pessoas no SUS e a responsável pela coordenação e ordenação do cuidado, inclusive no que se refere ao encaminhamento daquelas que necessitam ser atendidas nos pontos de atenção de diferentes níveis e densidades tecnológicas (BRASIL, 2010).

O que acontece na micropolítica? Cartografando a unidade básica do distrito de saúde de Luiza, a coordenadora da ESF explica os detalhes do cotidiano do serviço: Aqui nós atendemos muita demanda espontânea, o que dificulta o acompanhamento longitudinal de doenças crônicas. Além disso, há uma área desse território que é descoberta. Infelizmente, isso é uma realidade. (CESF).

Giovanella e Mendonça (2012) demonstram que sistemas de saúde com APS fortalecidas estáo associados a melhores resultados de saúde e a menores taxas de mortalidade, sobretudo relacionadas ao câncer, à doença cardiovascular, a 
doenças respiratórias, à mortalidade prematura e infantil. Além disso, indicam um aumento da expectativa de vida e melhoria na autopercepção de saúde dos usuários. $\mathrm{Na}$ micropolítica de Luiza, fica clara a escassez de recursos e investimentos na proposta de uma atençâo básica resolutiva aos diversos processos saúde-doença da população assistida.

Outra problemática é relatada pela enfermeira, acerca da fragilidade da relação entre o serviço de saúde e a comunidade:

Antigamente, tinha um posto dentro do bairro. Aí era tudo mais fácil, por que os profissionais já estavam no território e eram conhecidos. Mas tiraram o posto daqui por causa da violência. É um bairro muito perigoso, dominado pelo tráfico. O posto está agora em um lugar mais central, mas distante da comunidade (Enf).

Percebe-se que o câncer, enquanto fenômeno de saúde, alcança o nível de ser, também, um problema social. A análise da produção do cuidado, que consiste no estudo dos determinantes sociais de saúde (DSS), registra que os fatores socioeconômicos são apontados como elementos importantes na incidência e mortalidade por câncer. Travassos e Castro (2012) problematizam que a conjuntura social, com suas crises inerentes a sua lógica de funcionamento, se torna devastadora para qualquer esfera da atividade humana, afetando, de modo geral, as relaçóes humanas e, por conseguinte, a saúde.

Essas linhas cartográficas lembram o paradigma de que não é possível produzir saúde se estar for considerada um campo isolado da vida. A paisagem humana não é neutra; é rica em elementos variados. Sendo assim, reflete-se sobre a interrelação entre vulnerabilidade social e adoecimento oncológico. A história de Luiza vem afirmar que não é possível fazer cuidado em saúde sem percebê-la atrelada à singularidade de uma conjuntura política, social e econômica.

\section{A potência do território comunitário: redes que tecem vínculos e produzem vida}

Esta pesquisa se aproxima da concepção de território existencial (GUATTARI; ROLNIK, 1986), visto que essa perspectiva não emoldura apenas u m lugar geográfico; trata-se de um espaço que é biopsicossocial e envolve uma singularidade de valores, desejos, significados e sentidos. Tais compreensóes passam a ser imprescindíveis para a análise dos processos de cuidados que pulsam no território comunitário de Luiza. 
Foi nos encontros com o território comunitário de Luiza que se investigaram outras linhas que escapam do cuidado protocolar da rede formal de saúde, linhas que produzem saúde e que acolheram a usuária-guia Luiza desde a descoberta até sua reabilitação: vínculos comunitários e familiares; vínculo com a espiritualidade/ religiosidade. Luiza afirma a importância da rede familiar: "Na dor, na alegria e na tristeza, elas sempre estiveram comigo. Sempre”. Embora se registre tal potência na visão da usuária, foram perceptíveis o desgaste físico, emocional e as transformaçóes da dinâmica familiar após o adoecimento oncológico. Maria passou a se dedicar integralmente aos cuidados de Luiza; e Liliane passou a ocupar o lugar de cuidadora da casa.

Posto isto, também é preciso dar atenção à saúde dos cuidadores, o que também se apresenta como lacuna. Maria relata que: "Quando estou exausta e ela, de repente, tem uma crise... Eu largo tudo e vou cuidar dela. Mas às vezes cansa, sabe? Esse ritmo. É um desgaste". Nesse contexto, estudos apontam que em processos de adoecimentos, os cuidadores, uma vez que buscam fornecer um cuidado integral, passam a estar presentes em diversas atividades cotidianas, como alimentação, medicação e higiene, além do apoio emocional, afeto, carinho e atenção. Diante dessas intensidades, esses indivíduos modificam a sua rotina, expondo-se a sobrecargas físicas, sociais e emocionais. Maria e Liliane não recebem nenhum tipo de acompanhamento, nem como cuidadoras, nem como usuárias do SUS (OLIVEIRA; SOUZA, 2017).

Já no que se refere à conexão com religiosidade/espiritualidade, Luiza diz que "A minha fé me curou" e, dessa forma, aparece outro território que cuida, além dos cuidados clínico, médico, hospitalar e familiar: o campo espiritual, com sua fé e forte ligação com crenças e rituais simbólicos de sua religião Umbanda. Luiza estava mergulhada no sincretismo religioso, vivenciando rituais e crenças ligados à Umbanda: "Eu sou grata aos meu santos, que me fortaleceram nos momentos mais difíceis do tratamento". A conexão de Luiza com a religiosidade, portanto, pode ser vista como uma movimentação de intensidades que indicam as múltiplas saídas para o retorno à vida, rompendo com os traçados duros, concretos e fechados dos encontros da vida.

$\mathrm{Na}$ oncologia, percebe-se a forte presença do denominado coping religioso no enfrentamento à experiência de ter câncer (VEIT; CASTRO, 2013). Este é definido como as possiblidades utilizadas pelas pessoas para a preservação de sua saúde quando passam por situaçóes que ameaçam sua integridade física e mental. 
A correlação entre religiosidade, espiritualidade e qualidade de vida em pacientes oncológicos caminha por duas vias (MELO et al., 2015). Por um lado, pessoas religiosas podem desenvolver estratégias de cuidados a partir de suas crenças, o que viabiliza melhor qualidade de vida diante do tratamento. Por outro, a própria experiência do adoecer oncológico impulsiona e favorece a busca pela espiritualidade e religiosidade como mecanismos de enfrentamento do sofrimento. A expectativa, ao traçar as linhas de cuidado da rede territorial de Luiza, buscou registrar que o físico, o social, o subjetivo, o intuitivo, o transcendente e o espiritual formam um só corpo e que, assim, toda forma de cuidado compreendendo tais dimensóes deve ser considerada, pois conformam a rede de criação da vida.

\section{"Ter câncer mudou minha vida": O que aprendemos com a cartografia de Luiza e os desafios do cuidado oncológico}

Embora as preconizaçóes políticas da rede oncológica afirmem um cuidado integralizado e ampliado, a cartografia de Luiza desenha encontros heterogêneos: ora capturam e aprisionam seus movimentos de produção de saúde, privilegiando a ausência da doença; ora potencializam as possibilidades de vida e de existência.

Luiza é uma mulher negra, em vulnerabilidade social, que transita por territórios do cuidado entre o biomédico, comunitário, existencial e espiritual. Embora seu tratamento oncológico da rede pública de saúde seja norteado mediante o poder e autoridade médica e o regime hospitalar, Luiza é uma usuária viva, que também é produtora de redes e que não opera guiada apenas pelo fluxo da produção clínica biológica do binário saúde/doença. Quando ela afirma que "ter câncer mudou minha vida", está desenhando o encontro com o câncer atrelado à linha da vida em movimento, em transformação diante das marcas do câncer e da experimentação do cuidado oncológico em seu corpo.

A usuária-guia convida a refletir que o cuidado oncológico atravessa múltiplas dimensóes, sejam físicas, sociais, econômicas, subjetivas e existenciais. Deste modo, urge a problemática da perspectiva das redes ampliadas e integrativas de cuidado articulada à promoção de saúde e qualidade de vida.

\section{Considerações finais}

A prática do cuidado em saúde pede a organização de uma gama de elementos e estratégias micropolíticas. Mulheres com câncer apresentam necessidades específicas 
que, por vezes, as redes assistenciais não conseguem ou não se dispóem a acolher. A rede de Luiza é um retrato da centralização do cuidado na alta complexidade, mas apresenta recursos comunitários como possibilidade de melhoria de saúde e qualidade de vida. É nítido enfatizar que a produção do cuidado de Luiza, que envolve família, religiáo e comunidade, acontece tangente à rede protocolar preconizada na rede oncológica.

Em suma, pode-se concluir que foi por meio da investigação micropolítica que se traçaram as linhas de vida, de fuga e de escape que abrangem a temática da integralidade do cuidado a mulheres com CCU, tendo a cartografia enquanto método, e o desenho das redes de Luiza como dispositivo disparador de análise e problematização, sem intenção de prescrever modelos de como gerir, organizar e produzir cuidado, mas de ir à busca por rupturas, territorializaçóes e reconfiguraçôes de linhas de pensamento, conhecimento e produção de cuidado na seara oncológica.

Ao findar este escrito, diante das discursividades e do modo operante desta pesquisa, urge a seguinte inquietação: quantas Luizas não estão caminhando na rede oncológica? Mulheres que nunca ouviram falar de prevenção, que apresentam severos problemas sociais transversalizados ao seu processo de cuidado, e que diante da experiência oncológica, criam redes de cuidado em seus territórios existenciais, seja com a religião/espiritualidade e/ou vínculos familiares? Será que as políticas que conformam as redes oncológicas têm ferramentas para lidar com mulheres e suas especificidades, articulando redes para além da assistência médico-hospitalar?

Finaliza-se este artigo alertando que existem uma multiplicidade de "Luizas" inseridas na rede oncológica que convocam os protagonistas do cuidado a perceber os gargalos existentes no processo de produção de redes de cuidado, convidando a quebrar os muros tecnoassistenciais e criar enfrentamentos pautados na ética da vida e não apenas na doença. A integralidade da atenção deve ser cotidianamente discutida nos espaços micropolíticos, seja no campo da gestão, nos hospitais e na atenção primária; é preciso que os serviços se adaptem e produzam inventividades diante das necessidades de cuidado dos usuários, e não o contrário.

Espera-se que esta pesquisa contribua para melhoria da assistência oncológica, afirmando a potência de vida e a promoção de saúde de mulheres com câncer. ${ }^{1}$ 


\section{Referências}

ALVES, S. R.; ALVES, A. O.; ASSIS, M. C. S. Educação popular em saúde como estratégia à adesão na realização do exame colpocitológico. Cienc Cuid Saude, v. 15, n. 3, p. 570-574, 2016. AMARAL, C. E. M.; BOSI, M. L. M. O desafio da análise de redes de saúde no campo da saúde coletiva. Saude soc. São Paulo, v. 26, n. 2, p. 424-434, jun. 2017.

BRASIL. Ministério da Saúde. Secretaria de Atenção à Saúde. Departamento de Açóes Programáticas Estratégicas. Portaria no 1.473/GM, de 24 de junho de 2011. Institui os Comitês Gestores, Grupos Executivos, Grupos Transversais e os Comitês de Mobilização Social e de Especialistas dos compromissos prioritários de governo organizados por meio de Redes Temáticas de Atenção à Saúde. Diário Oficial da República Federativa do Brasil. Brasília-DF, Seção 1, 25 jun. 2011.

. Ministério da Saúde. Portaria no 2.439/GM, de 08 de dezembro de 2005. Institui a Política Nacional de Atenção Oncológica: promoção, prevenção, diagnóstico, tratamento, reabilitação e cuidados paliativos. Diário Oficial da República Federativa do Brasil. Brasília-DF, p. 76, Seção 1,9 dez. 2005.

. Ministério da Saúde. Portaria no 4.279/GM, de 30 de dezembro de 2010. Estabelece diretrizes para a organização da Rede de Atenção à Saúde no âmbito do Sistema Único de Saúde (SUS). Diário Oficial da República Federativa do Brasil. Brasília-DF, 30 dez. 2010.

BRITO-SILVA, K. et al. Integralidade no cuidado ao câncer do colo do útero: avaliação do acesso. Rev. Saúde Pública. São Paulo, v. 48, n. 2, p. 240-248, abr. 2014.

DELEUZE, G.; GUATTARI, F. Como criar para si um corpo sem órgãos. In: . Mil platôs. v. 3. Tradução de Aurélio Guerra Neto et al. São Paulo: Ed. 34, 2008.

DELEUZE, G.; GUATTARI, F. Introdução: Rizoma. In: Mil platôs: capitalismo e esquizofrenia. v. 1. Rio de Janeiro: Editora 34, 1995, p. 10-36.

FRANCO, T. B. Trabalho criativo e cuidado em saúde: um debate a partir dos conceitos de servidão e liberdade. Saude soc., São Paulo. v. 24, supl. 1, p. 102-114, jun. 2015.

FRANCO, T. B.; MERHY, E. E. Cartografias do trabalho e cuidado em saúde. Revista Tempus Actas de Saúde Coletiva, v. 6, n. 2, p. 151-63, 2012.

GIOVANELLA, L.; MENDONÇA, M. H. M. Atenção Primária à Saúde. In: GIOVANELLA, L. et al. (Orgs.). Politica de Saúde no Brasil. 2.ed. Rio de Janeiro: Fiocruz, 2012. p. 575-595.

GUATTARI, F.; ROLNIK, S. Micropolitica: cartografias do desejo. Petrópolis: Vozes, 1986.

INSTITUTO NACIONAL DE CÂNCER. $A B C$ do câncer: abordagens básicas para o controle do câncer. 4. ed. rev. atual. Rio de Janeiro: INCA, 2018. 
- Coordenação de Prevenção e Vigilância. Divisão de Detecção Precoce e Apoio à Organização de Rede. Diretrizes brasileiras para o rastreamento do câncer do colo do útero. 2. ed. rev. atual. Rio de Janeiro: INCA, 2016.

- Coordenação de Prevenção e Vigilância. Estimativa 2018: incidência de câncer no Brasil. Rio de Janeiro: INCA, 2017.

MELO, C. F. et al. Correlação entre religiosidade, espiritualidade e qualidade de vida: uma revisão de literatura. Estud. pesqui. psicol. Rio de Janeiro, v. 15, n. 2, p. 447-464, jul. 2015.

MERHY, E. E. Saúde: a cartografia do trabalho vivo. 4. ed. São Paulo: Hucitec, 2014.

OLIVEIRA, P. E.; GUIMARÃES, S. M. F. Vivências e práticas de cuidado de mulheres em processo de tratamento de câncer. Ciênc. saúde coletiva. Rio de Janeiro, v. 20, n. 7, p. 2211-2220, jul. 2015.

OLIVEIRA, T. R.; SOUZA, J. R. Avaliação do impacto psicossocial do diagnóstico e tratamento do câncer na vida de familiares cuidadores de pacientes em regime de internação hospitalar. Tempus: Actas de saúde colet., Brasília, v. 11, n. 1, p. 215-227, mar. 2017.

PASSOS. S. E.; KASTRUP, V.; ESCÓSSIA, L. (Orgs.). Pistas do método da cartografia: pesquisaintervenção e produção de subjetividade. Porto Alegre: Sulina, 2010.

PINTO, A. M. S.; NAJAR, A. L. Cultura e instituiçóes de saúde: estudando a participação de traços culturais da sociedade brasileira no processo de trabalho de serviços de atenção básica. Ciênc. saúde coletiva. Rio de Janeiro, v. 16, n. 11, p. 4375-4384, nov. 2011.

RAUPP, L. M. et al. Doenças crônicas e trajetórias assistenciais: avaliação do sistema de saúde de pequenos municípios. Physis. Rio de Janeiro, v. 25, n. 2, p. 615-634, jun. 2015.

RICO, A. M.; IRIART, J. A. B. "Tem mulher, tem preventivo": sentidos das práticas preventivas do câncer do colo do útero entre mulheres de Salvador, Bahia, Brasil. Cad. Saúde Pública. Rio de Janeiro, v. 29, n. 9, p. 1763-1773, set. 2013.

ROLNIK, S. Cartografia sentimental. Porto Alegre: UFRGS, 2007.

SCHÖPKE, R. Por uma filosofia da diferença: Gilles Deleuze, o pensador nômade. Rio de Janeiro: Edusp, 2012.

SOARES, M. C. et al. Câncer de colo uterino: atenção integral à mulher nos serviços de saúde. Rev. Gaúcha Enferm. Porto Alegre, v. 32, n. 3, p. 502-508, set. 2011.

SONTAG, S. A doença e suas metáforas; AIDS e suas metáforas. Tradução de Rubens Figueiredo e Paulo Henrique Britto. São Paulo: Companhia das letras, 2007.

TEIXEIRA, L. A.; PORTO, M.; HABIB, P. A. B. B. Políticas públicas de controle de câncer no Brasil: elementos de uma trajetória. Cad Saude Publica. Rio de Janeiro, v. 20, n. 3, 2012. 
TRAVASSOS, C.; CASTRO, M. S. M. Determinantes e desigualdades sociais no acesso e na utilização de serviços de saúde. In: GIOVANELLA, L. et al. Políticas e sistema de saúde no Brasil. Rio de Janeiro: Editora Fiocruz/CEBES, 2012. p. 215-243.

VEIT, C. M.; CASTRO, E. K. Coping religioso/espiritual e câncer de mama: Uma revisão sistemática da literatura. Psic. Saúde \& Doenças, Lisboa, v. 14, n. 1, p. 1-22, mar. 2013.

\section{Nota}

${ }^{1}$ M. P. G. Cabra concebeu o estudo; realizou planejamento, coleta de dados, análise, interpretação, discussão dos dados e redação do artigo. M. S. B. Jorge orientou a pesquisa, participou da concepção do estudo, planejamento, coleta e interpretaçáo de dados, redação final e revisão crítica do artigo. T. B. Franco participou da elaboraçáo intelectual, delineamento, levantamentos, análises e interpretaçóes, discussão dos resultados, supervisionou a redação do artigo e colaborou com a revisão e aprovação da versão final. E. V. de Franca participou das análises, interpretaçôes, discussão dos resultados e redação do artigo. 


\section{Abstract}

\section{"Having cancer changed my life": Luiza's cartography in the micropolitics of cancer care networks}

Ensuring comprehensive health care for women with cervical-uterine cancer remains a challenge for public health, although evidence of the established policies, practices and knowledge in shaping of cancer care networks. This study focused on the need to deepen in the micropolitics of care experiments to know the nuances of the investigated phenomenon. Based on the theoretical and methodological approach of Deleuze and Guattari, it aimed to map the composition lines of cancer care production in the city of São Luis-MA, Brazil, using the network of the guide-user Luiza as a device. Twenty-eight participants were investigated through in-depth interviews and conversation groups. As a result, a vulnerable, fragmented, centralized network of biomedical care was designed, with a hospital that welcomes demands of the disease, and primary care that abandons prevention and health promotion. The importance of knowing women with cancer linked to the community, religiosity and family ties is highlighted. Having cancer changed Luiza's life and required connections beyond the biomedical sphere. This cartography calls for the perception of narrowing in the production of cancer care networks, inviting the breaking of techno-assistance walls and creating confrontations focused on health promotion and quality of life.

Keywords: cervical-uterine cancer; care; micropolitics; cartography; healthcare networks. 